\title{
THE
}

\section{A Comparison of Satellite and In Situ-Based Sea Surface Temperature Climatologies}

\author{
Kenneth S. Casey \\ University of Rhode Island \\ Peter C. Cornillon \\ University of Rhode Island, pcornillon@uri.edu
}

Follow this and additional works at: https://digitalcommons.uri.edu/gsofacpubs

\section{Citation/Publisher Attribution}

Casey, K. S., \& Cornillon, P. (1999). A Comparison of Satellite and In Situ-Based Sea Surface Temperature Climatologies. J. Climate, 12, 1848-1863. doi: 10.1175/1520-0442(1999)0122.0.C0;2.

Available at: https://doi.org/10.1175/1520-0442(1999)012<1848:ACOSAI>2.0.C0;2

This Article is brought to you for free and open access by the Graduate School of Oceanography at DigitalCommons@URI. It has been accepted for inclusion in Graduate School of Oceanography Faculty Publications by an authorized administrator of DigitalCommons@URI. For more information, please contact digitalcommons@etal.uri.edu. 


\title{
A Comparison of Satellite and In Situ-Based Sea Surface Temperature Climatologies
}

\author{
Kenneth S. Casey* and Peter Cornillon \\ Graduate School of Oceanography, University of Rhode Island, Narragansett, Rhode Island
}

(Manuscript received 2 September 1997, in final form 25 June 1998)

\begin{abstract}
The purpose of this study is to present a satellite-derived sea surface temperature (SST) climatology based on Pathfinder Advanced Very High Resolution Radiometer (AVHRR) data and to evaluate it and several other climatologies for their usefulness in the determination of SST trends. The method of evaluation uses two longterm observational collections of in situ SST measurements: the 1994 World Ocean Atlas (WOA94) and the Comprehensive Ocean-Atmosphere Data Set (COADS). Each of the SST climatologies being evaluated is subtracted from each raw SST observation in WOA94 and COADS to produce several separate long-term anomaly datasets. The anomaly dataset with the smallest standard deviation is assumed to identify the climatology best able to represent the spatial and seasonal SST variability and therefore be most capable of reducing the uncertainty in SST trend determinations.

The satellite SST climatology was created at a resolution of $9.28 \mathrm{~km}$ using both day and night satellite fields generated with the version 4 AVHRR Pathfinder algorithm and cloud-masking procedures, plus an erosion filter that provides additional cloud masking in the vicinity of cloud edges. Using the statistical comparison method, the performance of this "Pathfinder + erosion" climatology is compared with the performances of the WOA94 $1^{\circ}$ in situ climatology, the Reynolds satellite and in situ blended $1^{\circ}$ analysis, version 2.2 of the blended $1^{\circ}$ Global Sea-Ice and Sea Surface Temperature (GISST) climatology, and the in situ $5^{\circ}$ Global Ocean Surface Temperature Atlas (GOSTA).

The standard deviation of the anomalies produced using the raw WOA94 in situ observations and the reference SST climatologies indicate that the $9.28-\mathrm{km}$ Pathfinder + erosion climatology is more representative of spatial and seasonal SST variability than the traditional in situ and blended SST climatologies. For the anomalies created from the raw COADS observations, the Pathfinder + erosion climatology is also found to minimize variance more than the other climatologies. In both cases, the $5^{\circ}$ GOSTA climatology exhibits the largest anomaly standard deviations.

Regional characteristics of the climatologies are also examined by binning the anomalies by climatological temperature classes and latitudinal bands. Generally, the Pathfinder + erosion climatology yields lower anomaly variances in the mid- and high latitudes and the Southern Hemisphere, but larger variances than the $1^{\circ}$ climatologies in the warm, Northern Hemisphere low-latitude regions.
\end{abstract}

\section{Introduction}

Under the auspices of the World Meteorological Organization and the United Nations Environment Programme, the Intergovernmental Panel on Climate Change (IPCC) has published two major scientific assessments of the growing volume of climate research (Houghton et al. 1990; Houghton et al. 1996). In the second assessment, the IPCC identified the long-term, systematic, global observation of climate system parameters such as atmospheric carbon dioxide concentration,

* Current affiliation: Universities Space Research Association, NASA/Goddard Space Flight Center, Greenbelt, Maryland.

Corresponding author address: Dr. Kenneth S. Casey, Universities Space Research Association, Code 971, NASA/Goddard Space Flight Center, Greenbelt, MD 20771.

E-mail: casey@mohawk.gasc.nasa.gov air and ocean temperatures, and sea level as a priority topic in climate change research. Such observations can be used to assess the magnitude of climate change, examine temporal and regional variability, and initialize numerical climate models.

One of the more important climate parameters is sea surface temperature (SST), but the size of the World Ocean and the difficulty in taking measurements at sea preclude the establishment of a consistent in situ measurement network. Instead, observations from numerous volunteer observing ships (VOS) have been relied upon and compiled into large databases like the Comprehensive Ocean-Atmosphere Data Set (COADS) (Woodruff et al. 1993) and the U.K. Meteorological Office Historical SST databank (MOHSST4, MOHSST5) (Bottomley et al. 1990; Folland and Parker 1995). Despite the large volume of these collections and the large bin sizes used to average the individual observations into climatological means, some regions of the ocean remain 
poorly represented. As a result, it is difficult to accurately estimate climatic SST variations, which tend to be small compared to local variability and seasonal cycles, particularly in the Southern Hemisphere and far from established shipping lanes. Furthermore, the large bins, typically $5^{\circ}$ lat $\times 5^{\circ}$ long and 1 month in time, make SST anomaly determinations susceptible to noise introduced by SST variations across the binned region and time (Trenberth et al. 1992). The goal of this study is to develop a climatology based on satellite data that is better able to represent the spatial and temporal SST variability and will therefore be capable of producing an anomaly dataset with a smaller uncertainty level. Such a dataset can then be used to calculate SST trends with smaller uncertainties.

Satellite sensors provide an alternative approach to measuring SST from ships and provide the greater spatial and temporal sampling needed to generate a climatology more capable of characterizing local and seasonal SST changes. Five-channel Advanced Very High Resolution Radiometers (AVHRR/2), carried on board National Oceanic and Atmospheric Administration (NOAA) polar-orbiting satellites since 1981, provide twice-daily SST measurements of the cloud-free portions of the World Ocean. The sensors' two infrared channels in the $10-13-\mu \mathrm{m}$ atmospheric window enable high-quality atmospheric corrections (McClain et al. 1985). The AVHRR/2 sensors have the needed spatial and temporal resolution for climate studies, but persistent cloud contamination in some areas tends to reduce their effective coverage. Satellite-borne sensors have other problems that must also be addressed before using them to assemble a global SST climatology. The design and calibration of the sensor, atmospheric correction procedures, and presence of aerosols in the atmosphere all may limit the accuracy of the satellite-derived SST measurements (Brown et al. 1993). Furthermore, the technique used to remove cloud-contaminated measurements can significantly affect the satellite-estimated SST. Since retrievals contaminated by thin or small clouds show reduced SST values, using them in averages tends to depress the apparent mean temperature. It is thus particularly important to ensure the removal of such contaminated values before using the satellite fields in any climatological study. Care must also be taken when comparing in situ SST and satellite-derived SST, since the satellite sensors actually measure the skin surface temperature, which is on average $0.1^{\circ}$ to $0.2^{\circ} \mathrm{C}$ cooler than the bulk surface temperature as measured by buoys, ship intakes, and other in situ techniques (Schluessel et al. 1990; Clancy and Weller 1992).

Several algorithms have been used in the past to convert the AVHRR-measured radiances into SST values (McClain et al. 1985; Barton 1995). The most widely used of these is the NOAA operational suite, beginning with the Multi-Channel Sea Surface Temperature (MCSST) algorithm in 1981, followed by the crossproduct SST algorithm and then the nonlinear SST
(NLSST) algorithm (Walton 1988). These operational satellite SST datasets have been integrated into global SST climatologies to improve their ability to characterize the mean SST state. Nicholls et al. (1996), in the latest IPCC assessment (Houghton et al. 1996), added satellite data to their climatology from 1982 onward using a Laplacian blending technique (Reynolds 1988). A climatology combining in situ and satellite data and resolved to $1^{\circ}$ lat $\times 1^{\circ}$ long has also been achieved by optimal interpolation and correcting biases in the satellite data relative to the in situ observations (Reynolds and Smith 1995). Both of these climatologies give more weight to the VOS data because the satellite SST data used were obtained in an operational mode, which results in inconsistent and relatively low accuracy SST time series only marginally useful for inclusion in climate studies (Bates and Diaz 1991).

There are two primary factors that limit the operational satellite retrievals when compared to those obtained from retrospective algorithms. First, fewer in situ values are available to tune the algorithm because only a fraction of the in situ observations collected are accessible in near-real time. Second, sensor characterization at the time of operational processing was relatively poor; only recently have the AVHRR/2 sensors been carefully characterized (Brown et al. 1993). The NOAA-National Aeronautics and Space Administration (NASA) AVHRR Pathfinder program addresses both of these factors in its reprocessing of the AVHRR/2 data stream. This reprocessing is based on the NLSST algorithm (Walton 1988) and employs thermal-vacuum test results (Brown et al. 1993), an extensive buoy matchup database (Podesta et al. 1998), and improved cloud-clearing algorithms. In addition to improvements in overall calibration accuracy, the program also uses all available temperature retrievals, unlike the MCSST algorithm which subsampled the AVHRR/2 data stream at a relatively coarse resolution (JPL PO.DAAC 1998). The Pathfinder community-consensus algorithm also minimizes sensor drift error, and provides consistent processing of both daytime and nighttime SST retrievals at $9.28 \mathrm{~km}$ resolution. Four versions of the Pathfinder algorithm have been developed, with improvements being implemented at each stage between versions 1 and 4. More details on the four versions are given in the following section.

In this study, these improvements to the satellite dataset are tested by developing a global SST climatology from the AVHRR Pathfinder data, and a method is presented for evaluating both satellite-derived and in situbased climatologies for their ability to minimize the SST anomaly standard deviation, $\sigma$. This method is based on two sets of anomaly datasets created from SST climatologies and raw in situ SST observations. The first set of anomaly datasets are created by subtracting reference climatological SST values from the individual highquality SST observations found in the 1994 World Ocean Atlas (WOA94) collection (Levitus and Boyer 
(a)

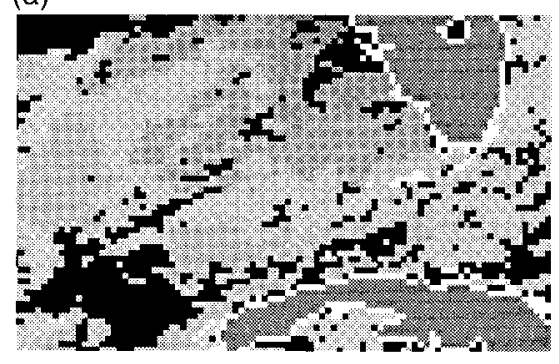

(b)

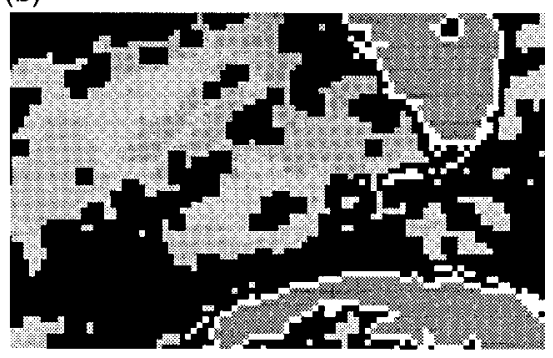

FIG. 1. Pathfinder cloud-masking and erosion filter. The left frame shows an example of the Pathfinder cloud-masking algorithm as applied to the Gulf of Mexico region in the 19 Feb 1989 nighttime Pathfinder image. The right frame shows the same image, but with the additional erosion filter applied. Areas covered by clouds are shown in black.

1994) of research ship data. These observations come mainly from expendable bathythermographs (XBT), conductivity-temperature-depth (CTD) probes, and hydrographic bottle casts. The second anomaly datasets are created by subtracting the SST climatologies from the VOS observations of SST in the COADS collection, which are mainly derived from engine intakes and various bucket types. These SST anomaly datasets are examined globally, and by latitudinal bands and climatological temperature classes to evaluate the performance of the SST climatologies. By identifying which climatology minimizes $\sigma$ in the anomaly datasets, the primary goal of selecting the most representative climatology for the determination of long-term SST trends is accomplished.

The construction of the Pathfinder + erosion satellite climatology, a review of the in-situ based and blended climatologies examined, the method of comparison, and the in situ data sources are detailed in section 2. Results of the comparison are presented in section 3, and a discussion focusing on the limited regions where the satellite climatology fails to outperform the other climatologies is given in section 4 .

\section{Data and methods}

\section{a. Pathfinder climatology}

Version 4 NOAA-NASA AVHRR Oceans Pathfinder fields from 1985 through 1995 were used to generate the satellite climatology. These fields were created at the Jet Propulsion Laboratory (JPL) by applying Eq. (1) at each pixel location to the AVHRR data stream:

$$
\begin{aligned}
\mathrm{SST}= & \alpha+\beta(T 4)+\gamma(T 4-T 5) T_{g} \\
& +\delta(T 4-T 5)(\sec \theta-1),
\end{aligned}
$$

where $T 4$ and $T 5$ represent the AVHRR/2 radiometer channel 4 and 5 radiances, $T_{g}$ is a first-guess SST based on weekly objective analysis SST fields (Reynolds and Smith 1994), and $\alpha, \beta, \gamma$, and $\delta$ are empirically determined coefficients. In version 1 of the Pathfinder algorithm, these calibration coefficients were calculated for three water vapor regimes on an annual basis at the
University of Miami by regression against a high quality moored and drifting buoy matchup database (Podesta et al. 1998). A time-dependent term was included in the algorithm as well. To better account for stronger aerosol biases introduced by the eruption of Mount Pinatubo in 1991, version 2 determined the coefficients over 5month running windows and so the time-dependent term was dropped. Using only two water vapor regimes instead of three was found to lower the overall bias between satellite and buoy SST over a greater range of environmental conditions (JPL PO.DAAC 1998), so the change was made in version 3 . Version 4 employs coefficients determined for two water vapor regimes using the 5-month running windows, and also implements improved cloud-masking techniques and a robust coefficient estimation scheme. One field each day and night during the time period was created by remapping the equal-area data to a global, equal-angle $4096 \times 2048$ pixel grid with a resolution of $9.28 \mathrm{~km}_{\text {pixel }}{ }^{-1}$. Nearly 8000 fields from the $11 \mathrm{yr}$ were generated using the version 4 algorithm. Pre-1985 data have not yet been processed by JPL through the Pathfinder algorithm.

Pixels contaminated by clouds were first identified using the Pathfinder cloud-masking algorithm, which uses channel difference tests and a comparison to a reference field (JPL PO.DAAC 1998). This algorithm was applied at JPL at the same time the SST fields were created. The standard cloud-masking routine, however, has difficulty making cloudiness determinations for pixels adjacent to cloudy regions, where SST values may be slightly reduced by the presence of thin or subpixel clouds common in the vicinity of cloud edges. Therefore, an erosion filter was applied to the Pathfinder declouded fields to yield a "Pathfinder + erosion" dataset. The erosion filter masks as cloudy any pixel immediately adjacent to a pixel identified as cloudy by the standard cloud-masking algorithm. Figure 1 shows a portion of a Pathfinder SST field before and after erosion. The erosion filter was applied after the fields had been remapped to the equal-angle projection.

The Pathfinder + erosion daily fields were then averaged to generate a satellite-based SST climatology. 
(a)

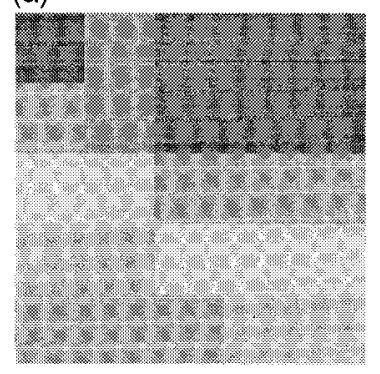

(b)

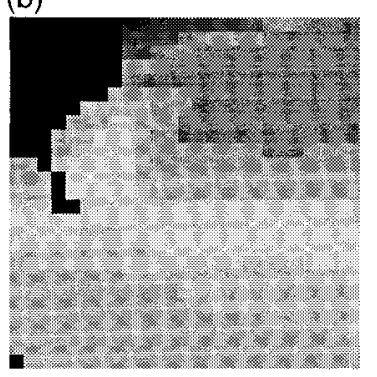

(c)

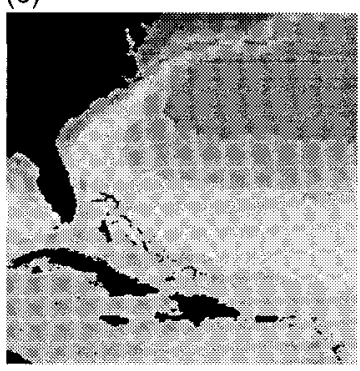

FIG. 2. A comparison of spatial resolutions for three SST climatologies. The left frame shows a subset of the GOSTA $5^{\circ}$ climatology, the middle frame has a subset of the Reynolds $1^{\circ}$ analysis, and the right frame shows a subset of the 9-km Pathfinder + erosion climatology. All three frames cover the same area of the North Atlantic from approximately $15^{\circ}-40^{\circ} \mathrm{N}$ and $85^{\circ}-60^{\circ} \mathrm{W}$.

All day and night fields in each calendar month were averaged to yield 12 monthly climatological mean SST fields. For example, all January day and night fields from the Pathfinder + erosion dataset were averaged for the 11 Januarys in 1985-95 to give a climatological mean January. Averaging of the SST fields was performed at the full $9.28-\mathrm{km}$ resolution. A similar climatology generated using the noneroded fields was also constructed.

The $9.28-\mathrm{km}$ monthly climatologies were nearly spatially complete for the entire globe. However, in areas of persistent cloudiness some gaps remained. These gaps were filled first with the median temperature of the surrounding SST values from the $7 \times 7$ pixel box centered on the missing pixel. Remaining gaps were then replaced with the linearly interpolated value from the previous and following climatological months. Since these months had gaps of their own, a few small gaps could still remain in the current month. These were then filled by using the median value as in the first step. On average, only about $8 \%$ of the total number of pixels in each climatological month were missing, with nearly all of these occurring in the high latitudes. Less than $1 \%$ of the pixels between $60^{\circ} \mathrm{N}$ and $60^{\circ} \mathrm{S}$ were missing a value. Since the Pathfinder algorithm does not explicitly identify sea ice, the climatology and any results derived from it must be treated with caution in the ice-prone high-latitude regions.

\section{b. In situ climatologies}

Four of the most widely used in situ-based climatologies were selected for comparison with the Pathfinder + erosion climatology. The first of these is the Global Ocean Surface Temperature Atlas (GOSTA) (Bottomley et al. 1990), which has been used in numerous studies of SST warming (Folland et al. 1990; Jones et al. 1991; Folland et al. 1992; Parker et al. 1994), either directly or as the basis of an improved analysis. The GOSTA climatology, created from VOS data found in MOHSST4, is resolved to $5^{\circ}$ lat $\times 5^{\circ}$ long and referenced to a $1951-80$ base period. Intermediate pro- cessing of pentad SST anomalies at a $1^{\circ}$ resolution is performed in an attempt to reduce the problem of SST variations across the binned region and time. A subset of 1-month of the GOSTA climatology for a region of the North Atlantic is shown in the first frame of Fig. 2. Note that Bottomley et al. (1990) also presented a climatology with a spatial resolution of $1^{\circ}$. However, to better illustrate the progressive improvement achieved with increased spatial resolution, the $5^{\circ}$ version was examined in this study.

The second in situ-based climatology selected was the optimally interpolated SST analysis of Reynolds and Smith (1995), which was created for use in the NOAA operational global SST analysis (Reynolds and Smith 1994). This climatology is resolved to $1^{\circ}$, and is based on $30 \mathrm{yr}$ of COADS data spanning 1950-79 and AVHRR/2 retrievals between 1982 and 1993. It is important to note that the AVHRR SST used in the Reynolds analysis is not the Pathfinder AVHRR SST, but rather satellite-derived SST determined using the operational MCSST and NLSST algorithms. The base period of the Reynolds climatology is adjusted to 195079 wherever sufficient in situ data are available. The middle frame of Fig. 2 illustrates the North Atlantic region of one month of the Reynolds climatology.

The third climatology is composed of high quality, research ship-collected SST observations from the WOA94 dataset (Levitus and Boyer 1994). Observations are collected into $1^{\circ}$ squares over the globe and compared with a "first-guess" SST based on $1^{\circ}$ zonal averages for the ocean basin in question. A correction factor based on the difference between the first-guess and the $1^{\circ}$ square mean is applied to the first-guess SST, and the results are median filtered to yield a monthly climatology resolved to $1^{\circ}$ lat $\times 1^{\circ}$ long. The WOA94 procedures were developed and applied to not only create temperature climatologies at the surface, but at standard depth levels as well. The WOA94 climatology should not be confused with the WOA94 collection of profile and SST data, which are the individual observations used to generate the climatology.

The fourth climatology, constructed using version 2.2 
of the Global Sea-Ice and Sea Surface Temperature (GISST) dataset (Parker et al. 1995), was created for climate change studies and quality control of individual SST observations. The GISST dataset uses the MOHSST6 database as its primary input (Rayner et al. 1996), applies improved corrections to account for the biases in bucket SST measurements made prior to 1942, and employs extensive filtering to produce a climatology resolved to $1^{\circ}$ and based on a 1961-90 reference period. Like the Reynolds climatology, GISST version 2.2 also includes non-Pathfinder AVHRR SST retrievals from 1982 to 1994.

\section{c. Evaluation method}

The SST anomaly $\sigma$ is used to evaluate the performance of the Pathfinder climatologies and the four selected in situ-based and blended climatologies. The climatology with the smallest $\sigma$ is given the highest performance rating. The technique yields detailed regional performance evaluations by constructing two SST anomaly datasets for each of the six climatologies being compared and calculating the anomaly $\sigma$ using several binning strategies.

The first SST anomaly dataset for each climatology is generated using the WOA94 collection (Levitus and Boyer 1994) of high quality surface temperature observations. These measurements were obtained from CTD, XBT, and hydrographic sampling bottles, and only observations from the standard depth of $0 \mathrm{~m}$ with the highest quality flag in the standard depth profiles were selected. This process yielded nearly $2.6 \times 10^{6}$ observations between 1900 and 1993.

The second in situ dataset used to generate SST anomalies is the COADS collection of VOS data, consisting primarily of engine intake and bucket measurements. Only COADS observations between the years 1942 and 1995 were selected, since earlier observations require large corrections to account for the biases between the various types of buckets commonly used to measure SST. For the years 1942 to 1949, COADS Compressed Marine Records (CMR) were used, while for 1950-95, Long Marine Record Format (LMRF) data were available and were used for this analysis. The CMR and LMRF data yielded approximately $88.5 \times 10^{6} \mathrm{SST}$ observations.

An SST anomaly for each observation in each of the two in situ datasets is then obtained for each of the six climatologies, resulting in 12 anomaly datasets. An anomaly, $\mathrm{SST}_{x, y, t}^{\prime}$, is calculated by subtracting from the in situ SST observation, $\mathrm{SST}_{x, y, t}$, the climatological SST corresponding to that location and time, $\overline{\mathrm{SST}}_{x, y, t}$ :

$$
\mathrm{SST}_{x, y, t}^{\prime}=\mathrm{SST}_{x, y, t}-\overline{\mathrm{SST}}_{x, y, t} \text {. }
$$

The climatological SST is calculated by linearly interpolating the monthly climatologies to the day of the observation, where the monthly SST values are assumed to fall on the middle day of each month. Also, for the $1^{\circ}$ and $5^{\circ}$ climatologies, spatial weighting is performed using SST values from the four closest grid points to give an interpolated climatological SST at the location of the in situ measurement. If any of the nearest grid points does not contain a valid SST, the interpolation is performed using the remaining values. For each of the climatologies, this technique yielded a climatological SST associated with each in situ observation.

Many SST observations used to calculate the anomalies can be densely packed in space and time. The observations in these dense groupings are not independent of one another, so a hierarchical clustering (Gong and Richman 1995) was performed on the WOA94 anomalies. Clustering replaces the closely packed observations with a single averaged value, thereby preventing the densely clustered observations from being inappropriately weighted in subsequent areal averages and giving an improved estimate of the true number of independent observations. To this end, clusters were defined by a sphere with a spatial radius of $10 \mathrm{~km}$ and temporal radius of 2 days. These parameters strike a balance between scales that are so small that observations are rarely clustered, and scales that are so large that they increase ambiguity by averaging observations located in different oceanic features such as large eddies and major currents, which generally have larger spatial and temporal scales than the ones chosen here (Cushman-Roisin 1994). Additionally, clustering reduces the random noise associated with individual SST measurements within the cluster sphere.

The clustering technique required two passes through the list of observations. In the first pass, each observation was treated as the center of a cluster. All measurements falling within that cluster sphere were counted, and their mean distance from the center recorded. Distance was calculated using

$$
\text { distance }=\sqrt{\Delta x^{2}+\Delta y^{2}+\Delta t^{2}},
$$

where $\Delta x$ and $\Delta y$ are the latitudinal and longitudinal distances in $\mathrm{km}$. The temporal separation, $\Delta t$, is expressed in kilometers using

$$
\Delta t=\frac{\text { time difference in days } \times \text { spatial radius in } \mathrm{km}}{\text { temporal radius in days }} .
$$

The resulting cluster centers were then ranked first in descending order by the number of observations in a cluster and then, for clusters with the same number of observations, in ascending order by the mean separation distance. The second pass started with this ranked list and processed the largest, most closely packed cluster first. The mean cluster SST, standard deviation, and number of observations in the cluster were recorded, and all in situ values within the cluster were flagged so they would not be included in another cluster. The processing proceeded through the ranked list of the first pass. If the next ranked observation was already used 


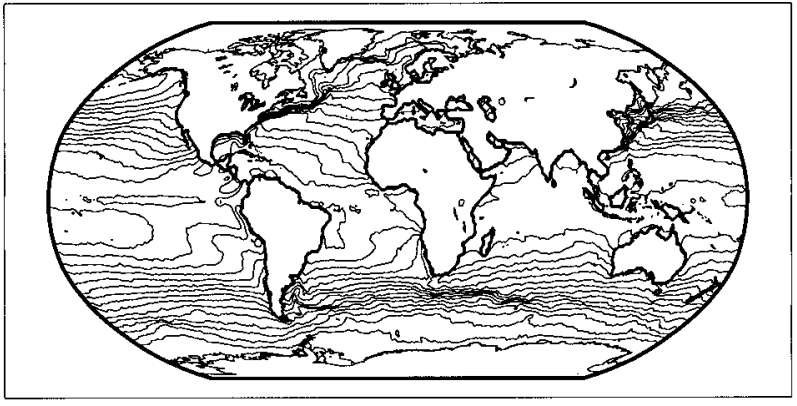

FIG. 3. Temperature classes for binning anomalies. The contours outline the Pathfinder + erosion temperature classes for March. Only every other temperature class contour is shown.

in a higher-ranked cluster, it was skipped. If it was not, then all of the unused observations in the cluster for which this observation was the center were reevaluated, and the one with the largest number of remaining observations was selected as the most representative cluster center. Its statistics were recorded, and processing continued until all observations had been included in at most one cluster. This technique produced what are known as "hard" clusters, indicating that no observation was used in more than one cluster (Gong and Richman 1995). The climatological SST values associated with each in situ observation were then collected into the same clusters and averaged. The cluster analysis was computer intensive, and so was not performed on the extremely large number of COADS observations.

The statistics for the COADS and clustered WOA94 anomalies were then examined from different perspectives by binning them in two ways. One approach was to group the anomalies by latitudinal band. The globe was divided into 17 latitudinal bands, two $15^{\circ}$ bands for observations falling poleward of $75^{\circ}$ lat, and $1510^{\circ}$ bands between $75^{\circ} \mathrm{S}$ and $75^{\circ} \mathrm{N}$.

The second approach was to group the anomalies by climatological temperature class. These classes are defined by the climatological mean temperature at the location of the observation. For example, if the mean monthly climatological SST for a given observation was $18.5^{\circ} \mathrm{C}$, then the anomaly was placed in the $18^{\circ}-19^{\circ} \mathrm{C}$ temperature class. Figure 3 shows the temperature class divisions for the month of March. The temperature classes are defined separately by each climatology, and their spatial locations change each month.

Within these groupings, the anomaly standard deviation, $\sigma$, was calculated using

$$
\sigma=\left[\frac{1}{N-1} \sum_{i=1}^{N}\left(\mathrm{SST}_{i}^{\prime}-\overline{\mathrm{SST}}\right)^{2}\right]^{1 / 2},
$$

where $N$ is the number of SST anomalies, $\mathrm{SST}_{i}^{\prime}$, in the group, and $\overline{\mathrm{SST}}$ is their mean. Anomalies with a magnitude greater than $8^{\circ} \mathrm{C}$ were excluded since they fall outside of physical limits, even in the eastern tropical Pacific where El Niño events cause large changes in
TABLE 1. The global standard deviation, $\sigma$, and the global mean, $\mu$, of the WOA94 anomalies for each climatology examined, in ${ }^{\circ} \mathrm{C}$.

\begin{tabular}{lcc}
\hline \hline \multicolumn{1}{c}{ Climatology } & $\sigma$ & $\mu$ \\
\hline Pathfinder, 9 km & 1.45 & -0.09 \\
Pathfinder + erosion, 9 km & 1.47 & -0.17 \\
GISST, $1^{\circ}$ & 1.55 & -0.13 \\
Reynolds, $1^{\circ}$ & 1.58 & -0.08 \\
WOA94, $1^{\circ}$ & 1.58 & -0.08 \\
GOSTA, 5 & 2.07 & -0.27 \\
\hline
\end{tabular}

SST (Parker et al. 1994). The few anomalies flagged by this check were nearly always caused by obviously erroneous SST observations, not by incorrect climatological SST values.

\section{Results}

\section{a. WOA94 in situ observations}

Table 1 lists the overall statistics for the comparisons made against the WOA94 in situ observations. All (in situ minus daily climatological) SST anomalies with a magnitude of less than $8^{\circ} \mathrm{C}$, from all times and regions of the globe, were incorporated into these statistics. The 9-km Pathfinder climatology anomalies, with and without the erosion filter, have the smallest $\sigma$ at $1.47^{\circ} \mathrm{C}$ and $1.45^{\circ} \mathrm{C}$, respectively, while the GOSTA climatology anomalies have the largest $\sigma$ at $2.07^{\circ} \mathrm{C}$. The values of $\sigma$ are based on approximately $1.9 \times 10^{6}$ WOA94 observations, reduced from nearly $2.6 \times 10^{6}$ by the clustering technique. Owing to these large number of observations, statistical $\mathrm{F}$ tests indicate that $\sigma$ differences of less than $0.01^{\circ} \mathrm{C}$ are significant at the $99 \%$ confidence level. In the following results, all stated differences are verified for significance at the $99 \%$ confidence level using this statistical test.

The results in Table 1 for the in situ-based climatologies were obtained using clustered anomalies relative to spatially interpolated and temporally interpolated climatologies. Each of these steps reduced $\sigma$ over those obtained using unclustered anomalies generated from the monthly, nearest gridpoint SST climatologies. For the Reynolds climatology, $\sigma$ without clustering and without spatial or temporal interpolation was $1.73^{\circ} \mathrm{C}$. Adding temporal interpolation decreased this value to $1.67^{\circ} \mathrm{C}$, and adding spatial interpolation further decreased the value to $1.66^{\circ} \mathrm{C}$. Clustering these values resulted in the $\sigma$ value presented in Table 1 of $1.58^{\circ} \mathrm{C}$. Spatial interpolation alone reduced the $\sigma$ values for the $1^{\circ}$ climatologies by $0.01^{\circ}-0.02^{\circ} \mathrm{C}$, and by $0.10^{\circ} \mathrm{C}$ for the $5^{\circ}$ GOSTA climatology. Temporal interpolation alone reduced $\sigma$ for all four in situ climatologies by $0.06^{\circ} \mathrm{C}$ on average, and clustering alone by $0.07^{\circ} \mathrm{C}$.

The Pathfinder results in Table 1 were calculated using clustered anomalies relative to temporally interpolated climatologies. Since these climatologies are already highly resolved in space, no spatial interpolation was performed. Before clustering and temporal inter- 
polation, the Pathfinder + erosion $\sigma$ was $1.67^{\circ} \mathrm{C}$. Interpolating to the daily level lowered this value to $1.58^{\circ} \mathrm{C}$, and clustering further reduced the value to $1.47^{\circ} \mathrm{C}$, the value shown in Table 1 . Similar improvements were seen in the noneroded Pathfinder climatology.

The bias of the SST anomalies generated using the Pathfinder + erosion climatology was found to be $0.08^{\circ} \mathrm{C}$ colder than the bias of the anomalies calculated using the Pathfinder climatology, indicating the satellitederived SST values tend to be depressed in the vicinity of clouds relative to what their values would have been had clouds not been nearby. Since cloud contamination tends to lower the temperature of a pixel as seen from space, this cold bias in the SST retrievals adjacent to clouds suggests that on average these pixels are in fact cloud contaminated despite not having been flagged by the Pathfinder cloud-screening algorithm. This cloud contamination is most likely due to subpixel clouds or very thin clouds, which will neither depress the SST retrieval nor elevate its reflectivity sufficiently to be flagged by the Pathfinder declouding routine. For this reason, and because the variances of the Pathfinder and Pathfinder + erosion climatologies are similar, the Pathfinder + erosion climatology is chosen for comparison with the $1^{\circ}$ and $5^{\circ}$ climatologies. It is not appropriate, however, to use the bias of the other climatologies as a measure of their performances when comparing them with one another or with the Pathfinder + erosion climatology because they are based on different reference periods.

As noted above, the characteristics of each climatology are illustrated with two different binning strategies to group the anomalies. Binning by climatological temperature class and hemisphere, and scaling the horizontal axis by the percentage of the ocean surface area that the class occupies (Fig. 4), illustrate general trends toward larger $\sigma$ in the middle temperature classes and lower $\sigma$ in the warmest temperature classes for all climatologies. A peak is also seen in the very warmest class for all climatologies, which covers significantly less than $1 \%$ of the total ocean surface area. This peak results from the geographical location of this class, which is generally found along the north coast of Australia and around Indonesia. The coastal regions tend to experience higher variability, which results in higher anomaly $\sigma$ values.

The Pathfinder + erosion $\sigma$ are the smallest in nearly all Northern Hemisphere temperature classes between $2^{\circ} \mathrm{C}$ and $27^{\circ} \mathrm{C}$, except for a few classes where $\mathrm{F}$ tests indicate the satellite and $1^{\circ}$ climatologies exhibit statistically indistinguishable values as shown by the horizontal bars in Fig. 4a. The $1^{\circ}$ climatologies have the lowest $\sigma$ for the Northern Hemisphere classes warmer than $27^{\circ} \mathrm{C}$. In the Southern Hemisphere, the WOA94 climatology has the smallest $\sigma$ in classes warmer than $25^{\circ} \mathrm{C}$, but some of these values are shared by the other climatologies. It also has the lowest values in classes colder than $6^{\circ} \mathrm{C}$, though the Pathfinder + erosion and the other $1^{\circ}$ climatologies share many of these low values. In the Southern Hemisphere classes between $5^{\circ} \mathrm{C}$ and $24^{\circ} \mathrm{C}$, the Pathfinder + erosion climatology has the lowest $\sigma$, though some of these are shared with the $1^{\circ}$ climatologies. The Pathfinder + erosion and $1^{\circ}$ climatologies show smaller $\sigma$ than the $5^{\circ}$ GOSTA climatology everywhere. Since the WOA94 climatology was created using the same raw in situ SST observations used to generate the anomalies from which these values of $\sigma$ were computed, it was removed from the comparisons and the remaining climatologies were examined (Fig. 4b). In these comparisons, the Pathfinder + erosion climatology has the lowest values in all but a few of the temperature classes.

Plotting the anomaly $\sigma$ by latitudinal band and scaling the horizontal axis by the surface area of the globe occupied by each band reveals peaks in the midlatitudes of both the Northern and Southern Hemispheres (Fig. $5 c)$. The low latitudes are characterized by relatively small $\sigma$ for all climatologies, as are the Southern Hemisphere high latitudes. The Northern Hemisphere high latitudes, however, show $\sigma$ comparable to the midlatitude values.

The Pathfinder + erosion climatology has the lowest $\sigma$ in the $70^{\circ} \mathrm{N}$ to $30^{\circ} \mathrm{N}$ and $10^{\circ} \mathrm{N}$ to $50^{\circ} \mathrm{S}$ bands, and shares the smallest value with the WOA94 climatology in some of these bands (Fig. 5a). The WOA94 values for $\sigma$ are smallest south of $50^{\circ} \mathrm{S}$, and in the low latitudes from $20^{\circ} \mathrm{N}$ to $10^{\circ} \mathrm{S}$. The GISST climatology has the smallest $\sigma$ in the $80^{\circ} \mathrm{N}$ band. The largest differences between the Pathfinder + erosion and $1^{\circ}$ resolution climatologies occur in the midlatitudes where the Pathfinder + erosion climatology has the smallest $\sigma$, and at $10^{\circ} \mathrm{N}$ where the WOA94 climatology has the smallest values. As in the temperature class binning scheme, the GOSTA climatology exhibits the largest $\sigma$, with values nearly $1.0^{\circ} \mathrm{C}$ larger than the corresponding Pathfinder + erosion values in the midlatitudes, and about $0.3^{\circ} \mathrm{C}$ at the equator. Note that all climatologies experience elevated $\sigma$ in the equatorial band when compared to the adjacent bands. Excluding the WOA94 climatology from the comparison (Fig. 5b) indicates the Pathfinder + erosion climatology has the lowest values of $\sigma$ in nearly all latitudinal bands except those in the low-latitude Northern Hemisphere, where the GISST and Reynolds climatologies share the lowest values.

\section{b. COADS in situ observations}

Anomalies between the various reference climatologies and the COADS collection of VOS in situ SST observations were also calculated, and their overall $\sigma$ values are listed in Table 2. The values of $\sigma$ are significantly larger than those obtained with the WOA94 observations for all but the GOSTA climatology. Part, but not all, of this difference is due to the clustering used in the WOA94 analysis. The remainder of the dif- 

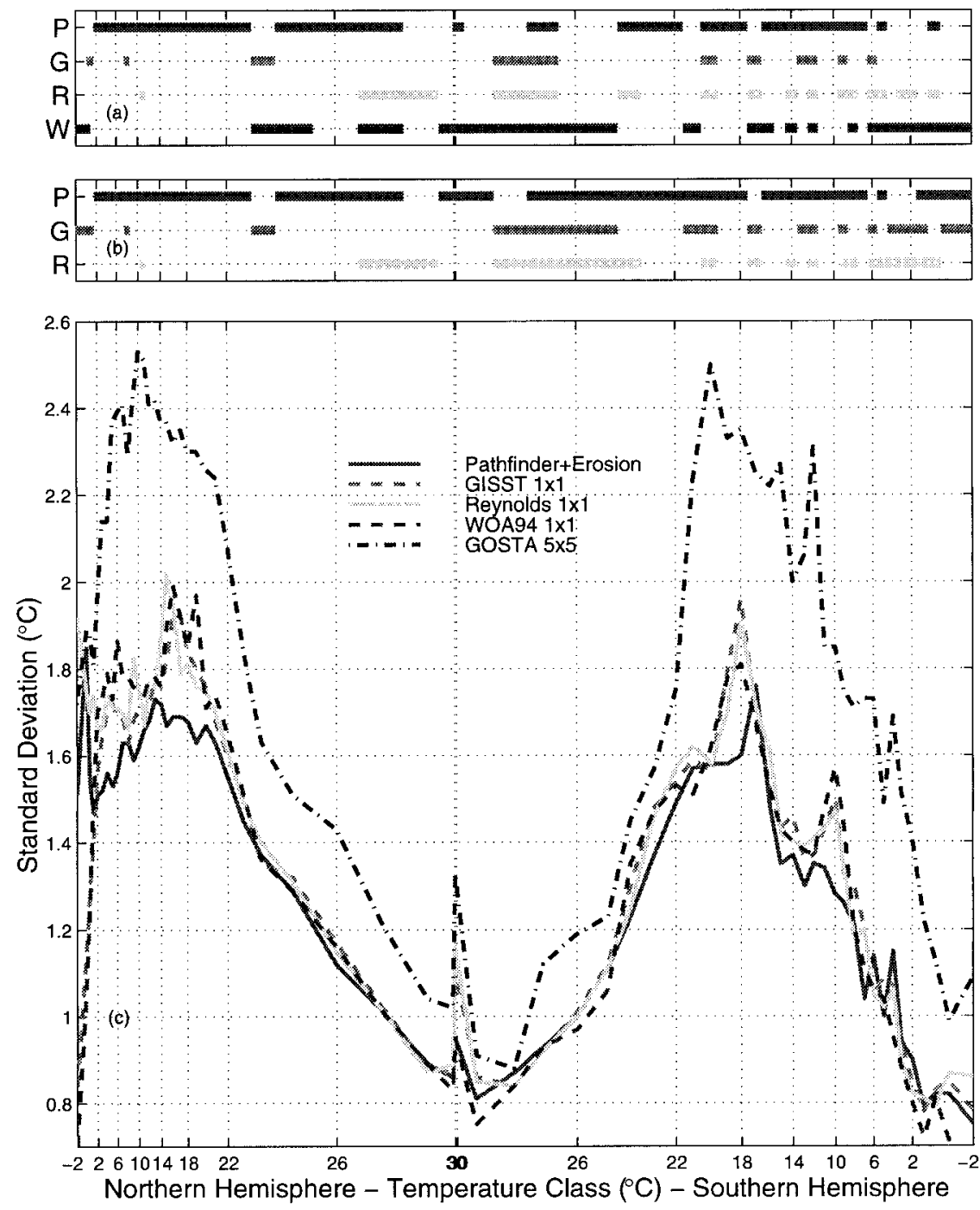

FIG. 4. Annually averaged standard deviations of WOA94 anomalies by temperature class. The smallest standard deviations among (a) all climatologies and (b) after excluding the WOA94 climatology are indicated by a horizontal bar. If more than one climatology is indicated for a given class, then their standard deviations are statistically indistinguishable: $\mathrm{P}=$ Pathfinder + erosion, $\mathrm{G}=$ GISST, $\mathrm{R}=$ Reynolds, and $\mathrm{W}=$ WOA94. (c) The standard deviations in ${ }^{\circ} \mathrm{C}$, and the horizontal axis is scaled by the percentage of the ocean surface area that each temperature class occupies.

ference is thought to result from the larger uncertainty associated with the bucket and engine intake temperatures compared with the more accurate hydrographic data.

The Pathfinder climatologies again have the smallest $\sigma$ as they did in the case of the WOA94 anomalies, but in this case the Pathfinder + erosion value of $1.64^{\circ} \mathrm{C}$ is smaller. Comparing the two reveals a similar amount of cloud-edge contamination as was seen in the WOA94 anomalies, with a $0.08^{\circ} \mathrm{C}$ warming of the climatology after application of the erosion filter. Because of the contamination of the noneroded Pathfinder climatology and its slightly larger values of $\sigma$, the satellite climatology results will focus on the Pathfinder + erosion values. The GOSTA climatology again shows the largest $\sigma$, with a value of $2.07^{\circ} \mathrm{C}$. The $\sigma$ values of the $1^{\circ}$ climatologies are more similar to the satellite value than they were in the case of the WOA94 observations. Approximately $88.0 \times 10^{6}$ individual COADS SST observations are used to generate these statistics.

The $\sigma$ values for the COADS anomalies are examined in the same manner as the WOA94 values. Figure 6 shows $\sigma$ by temperature class, revealing similar patterns as were seen in the WOA94 anomalies with generally higher values in the middle temperature classes and lower values in the warmer classes. In the Northern Hemisphere, the Pathfinder + erosion climatology has the smallest values for most temperature classes between 

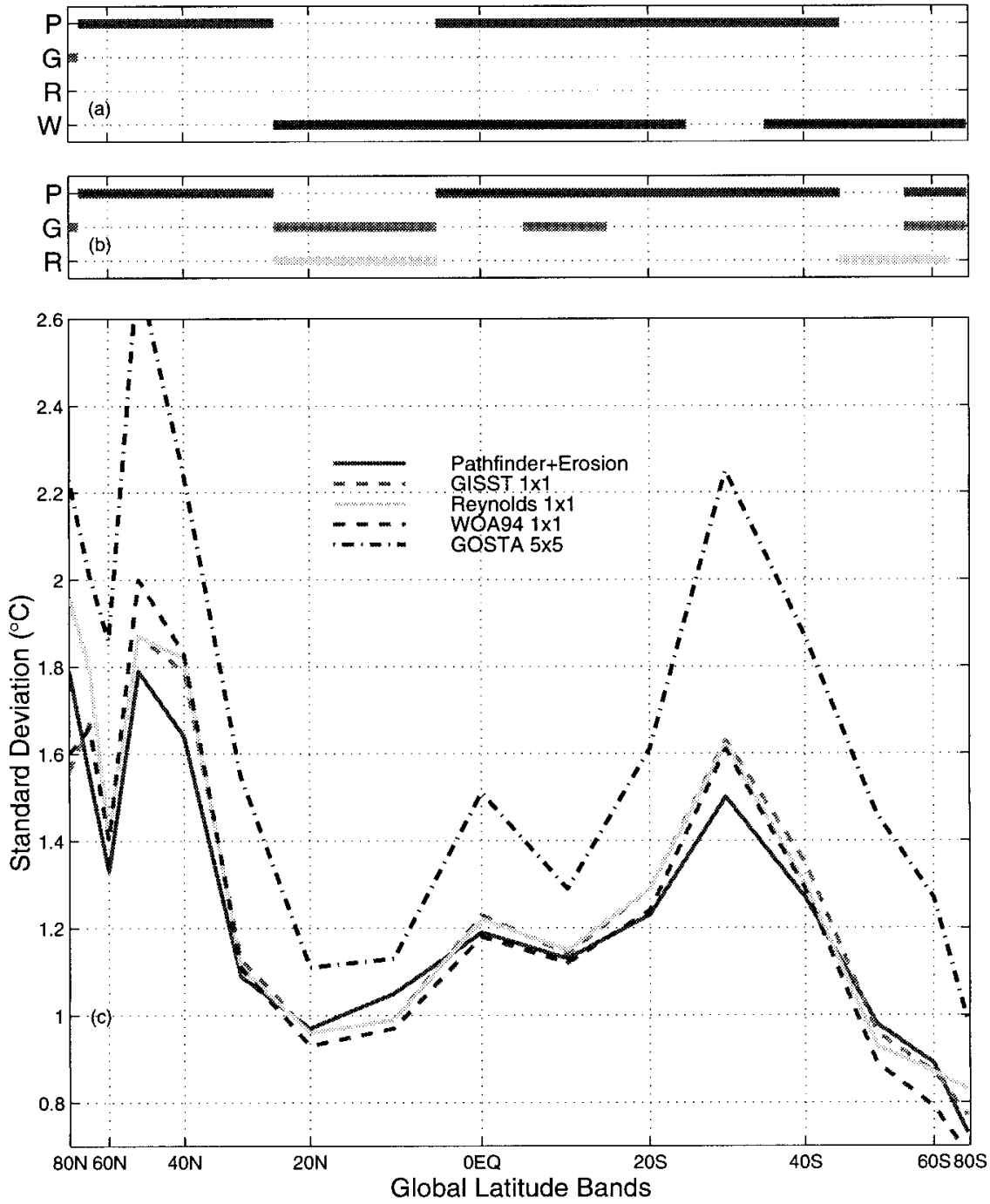

FIG. 5. Annually averaged standard deviations of WOA94 anomalies by latitudinal band. As in Fig. 4 but for latitudinal bands. The horizontal axis is scaled by the surface area of the ocean that the latitudinal band occupies.

$2^{\circ} \mathrm{C}$ and $23^{\circ} \mathrm{C}$. The GISST and Reynolds $\sigma$ are smaller for the $24^{\circ} \mathrm{C}$ and warmer temperature classes in both hemispheres. Again, all climatologies show a peak in the very warmest temperature class due to the proximity of that class to more highly variable coastal regions. In the Southern Hemisphere, the Pathfinder + erosion cli-

TABLE 2. The global standard deviation, $\sigma$, and the global mean, $\mu$, of the COADS anomalies for each climatology examined, in ${ }^{\circ} \mathrm{C}$.

\begin{tabular}{lcc}
\hline \multicolumn{1}{c}{ Climatology } & $\sigma$ & \multicolumn{1}{c}{$\mu$} \\
\hline Pathfinder, 9 km & 1.65 & 0.01 \\
Pathfinder + erosion, 9 km & 1.64 & -0.07 \\
GISST, $1^{\circ}$ & 1.69 & -0.04 \\
Reynolds, $1^{\circ}$ & 1.71 & 0.00 \\
WOA94, $1^{\circ}$ & 1.72 & -0.01 \\
GOSTA, $5^{\circ}$ & 2.07 & -0.10 \\
\hline
\end{tabular}

matology has the smallest $\sigma$ for all but one class colder then $24^{\circ} \mathrm{C}$.

Plotting the COADS anomaly $\sigma$ by latitudinal band (Fig. 7) reveals similar values for the $1^{\circ}$ and Pathfinder + erosion climatologies in the Northern Hemisphere but larger differences in the Southern Hemisphere. In the $70^{\circ}-30^{\circ} \mathrm{N}$ bands and in most bands in the Southern Hemisphere, the Pathfinder + erosion climatology has the smallest $\sigma$, but in the low latitudes of the Northern Hemisphere the GISST climatology has the smallest values. The $5^{\circ}$ GOSTA climatology exhibits the largest $\sigma$ values at all latitudes.

Examining the anomaly $\sigma$ seasonally in Fig. 8 reveals very little seasonal variation in the patterns by latitude band. An increase in $\sigma$ in the bands north of $50^{\circ} \mathrm{N}$ is observed during July, August, and September, and a sharp increase is seen at $70^{\circ} \mathrm{S}$. The value at $70^{\circ} \mathrm{S}$ how- 

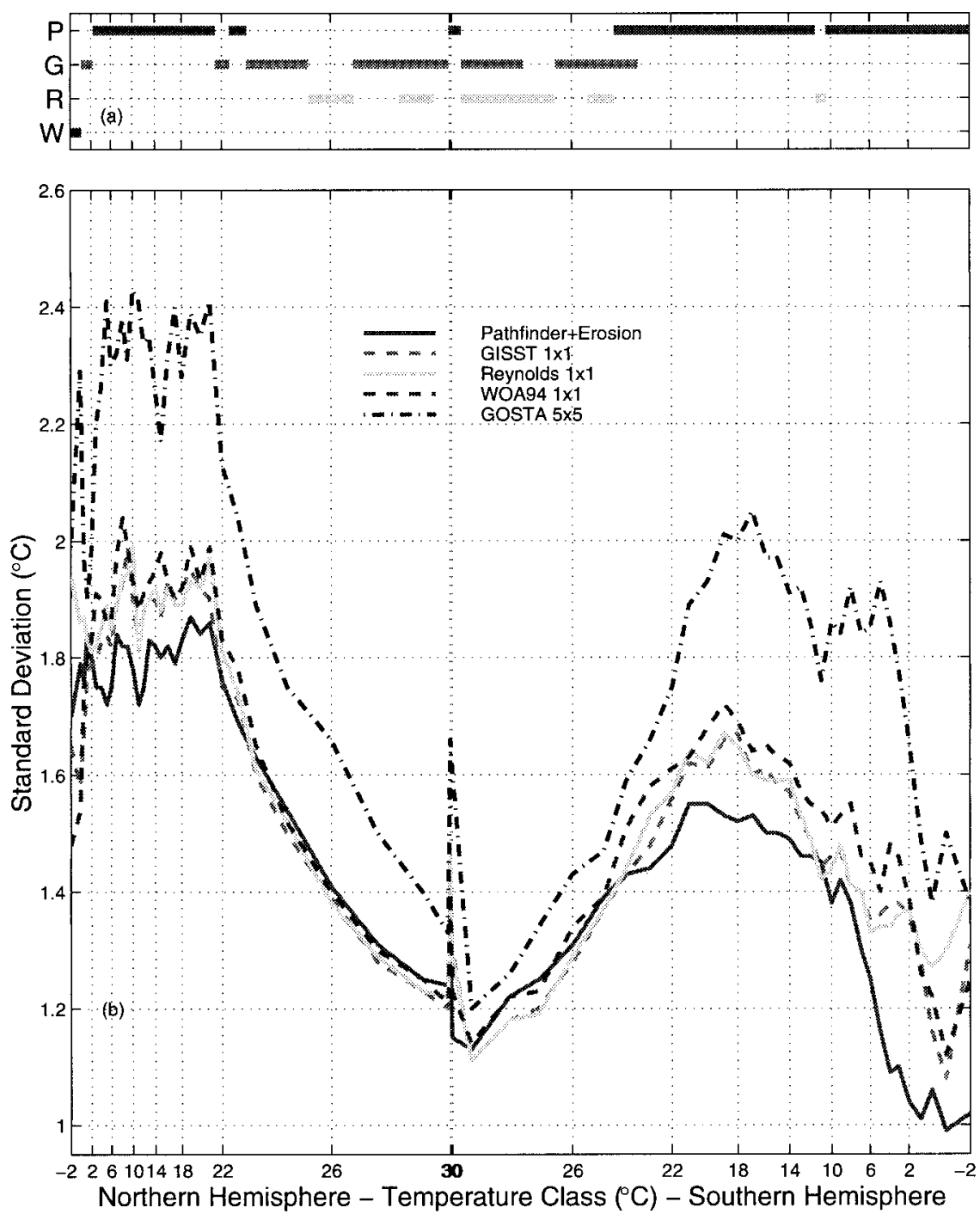

FIG. 6. Annually averaged standard deviations of COADS anomalies by temperature class. The smallest standard deviations among all climatologies are indicated by a horizontal bar in (a), and the standard deviations are given in (b). The horizontal axis is scaled by the area occupied by the temperature class, as in Fig. 4.

ever is a result of only five observations, while all other bands contain between roughly $1.7 \times 10^{4}$ and $4.2 \times$ $10^{6}$ observations.

\section{Discussion}

A new SST climatology developed from 11 yr of "eroded" Pathfinder AVHRR data from 1985 through 1995 has been presented. The application of the erosion filter to the Pathfinder-declouded SST images removes additional pixels that are thought to be cloud contaminated and warmed the resulting climatology by $0.08^{\circ} \mathrm{C}$. Although the 11-yr base period for this climatology is somewhat shorter than the $30 \mathrm{yr}$ generally used for in situ climatologies, the abundance of Pathfinder SST data allowed for the generation of nearly complete mean fields for each calendar month at a resolution of approximately $9 \mathrm{~km}$. Only limited gaps remained, and these were filled with simple filtering and interpolating procedures. No special consideration was given to the polar regions, however, where missing climatological SST values could be the result of either persistent cloud cover or the presence of sea ice. The addition of seaice information to the climatology may obviate the need for gap-filling completely.

A means of testing SST climatologies by their ability to minimize the standard deviation, $\sigma$, in anomaly fields has also been presented. The anomaly $\sigma$ values describe the width of their distribution, which includes both geophysical signal and measurement and climatology-un- 

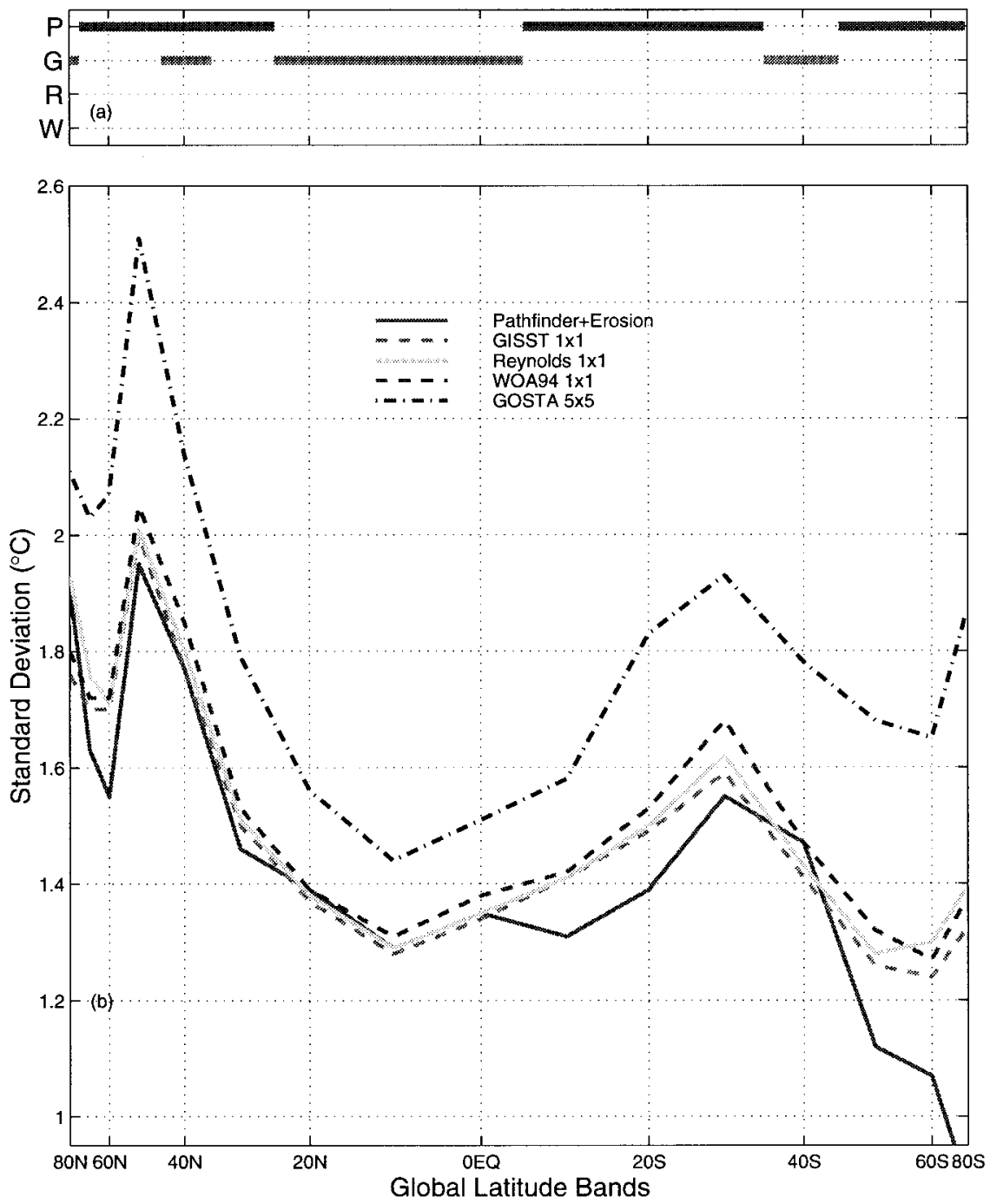

FIG. 7. Annually averaged standard deviations of COADS anomalies by latitudinal band. The standard deviation of anomalies are shown as in Fig. 6 but for latitudinal bands instead of temperature classes.

certainty noise components. This statistical comparison method assumes that the climatology best able to minimize $\sigma$ is best able to limit the noise components and can therefore be identified as the climatology most representative of spatial and seasonal SST variability. The $\sigma$ values can be examined annually or seasonally by latitudinal band or temperature class to give specific information regarding the characteristics of the climatologies being tested. The anomalies used in this approach are generated from individual observations first and can then be averaged using various binning strategies, unlike the anomalies computed using standard, monthly, geographic bin means (Nicholls et al. 1996; Parker et al. 1994). Generating individual anomalies first instead of calculating them in bins can also reduce or eliminate the significant errors that are introduced by seasonal cycle variations and spatial SST gradients pres- ent within the monthly, $1^{\circ}$ or $5^{\circ}$ bins generally used (Trenberth et al. 1992).

Because of the substantial SST variations that can exist between grid points in the $1^{\circ}$ and $5^{\circ}$ climatologies, interpolating the nearest gridded SST values to the location of the WOA94 and COADS in situ SST observations was performed. This procedure was found to reduce the $\sigma$ values obtained. Similarly, since SST variations also exist in time between the monthly climatological SST estimates, temporal interpolation to the daily level was performed and found to decrease $\sigma$ by about $0.08^{\circ} \mathrm{C}$ for the Pathfinder climatologies and by $0.06^{\circ} \mathrm{C}$ for the in situ-based and blended climatologies. These interpolation procedures allowed for the creation of a set of daily, spatially collocated SST anomalies for each climatology. More sophisticated temporal interpolation procedures for calculating the climatologies 

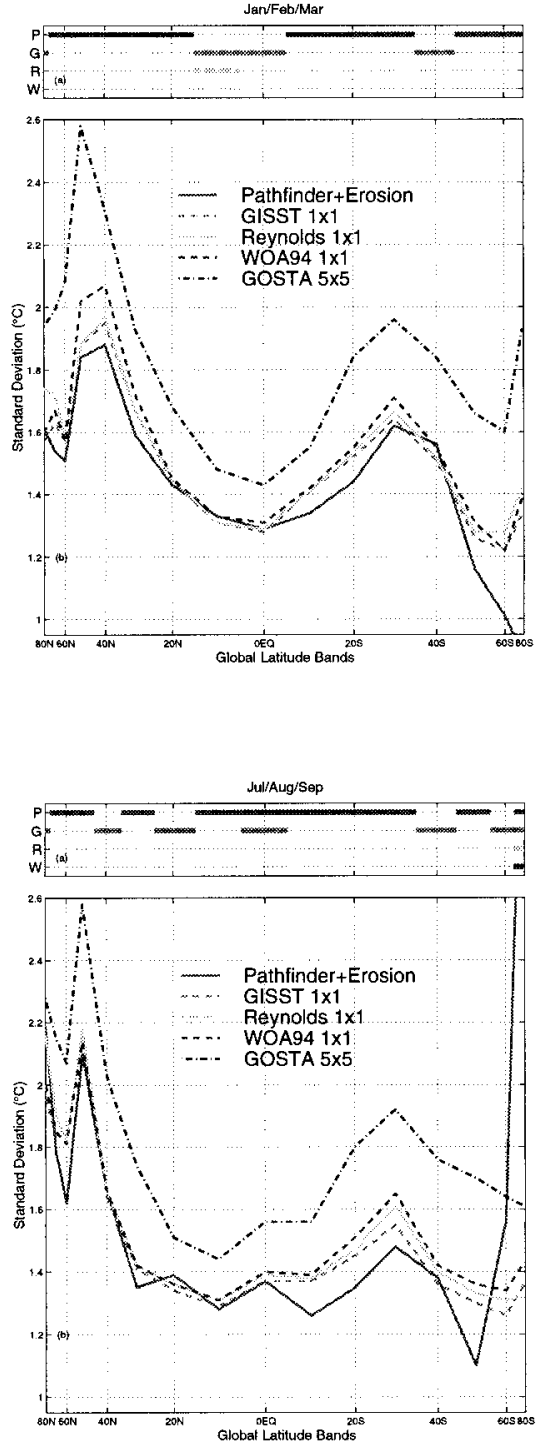
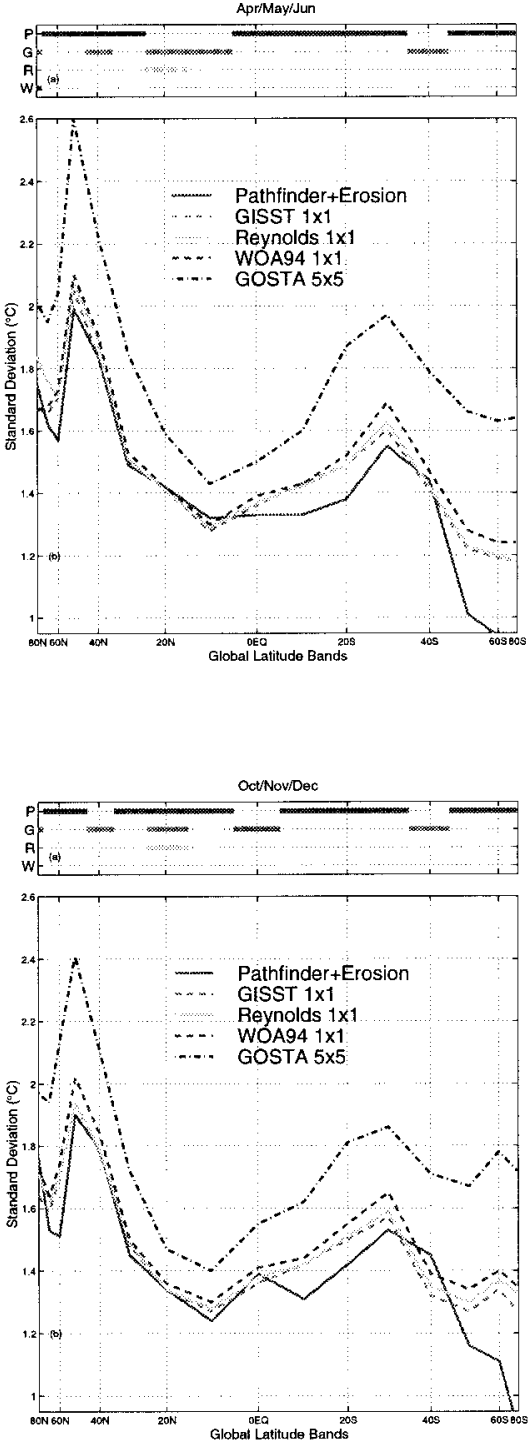
standard deviations are shown as in Fig. 7 but separately for four seasons.

over weekly or 5-day periods would likely further decrease the anomaly $\sigma$ levels.

For the WOA94 anomalies, the Pathfinder + erosion climatology had the smallest overall $\sigma$ by $0.08^{\circ} \mathrm{C}$ or more when compared to the in situ and blended climatologies, and this climatology had the smallest COADS anomaly $\sigma$ by $0.05^{\circ} \mathrm{C}$ or more. Computing the COADS anomaly $\sigma$ for each climatology using only the in situ data from its reference period increased the gap between the Pathfinder + erosion climatology and the other climatologies to $0.11^{\circ} \mathrm{C}$ or more. Differences of $0.01^{\circ} \mathrm{C}$ are significant at the $99 \%$ confidence level. More detailed examinations of the COADS anomalies reveal the Pathfinder + erosion climatology generally performed as well or better than the others except in the warm, low-latitude regions, especially in the Northern
Hemisphere around $10^{\circ}-20^{\circ} \mathrm{N}$. This general pattern was also reflected in the WOA94 anomalies.

The poor performance of the Pathfinder + erosion climatology relative to the in situ and blended climatologies in the low latitudes may indicate the presence of atmospheric aerosols, persistent cloud cover, high water vapor content, or some combination of these factors which may lead to problems in the Pathfinder SST algorithm. Monthly mean global aerosol optical depth measurements taken from the AVHRR sensor (Schollaert 1996) show the highest levels of aerosol contamination in the eastern equatorial North Atlantic in AprilSeptember and in the Arabian Sea in July and August, consistent with the relatively higher $\sigma$ observed. These high aerosol value regions are also observed to spread, reaching their maximum northward extent in July 
around $25^{\circ} \mathrm{N}$. An earlier version of the Pathfinder + erosion climatology, constructed from $4 \mathrm{yr}$ of version 1 data, experienced elevated anomaly $\sigma$ values that closely tracked these aerosol trends. The Pathfinder + erosion climatology created using version 4 data still shows slightly poorer performance than the $1^{\circ}$ climatologies in the low latitudes, but the differences are smaller than they were previously and do not clearly track the changing aerosol concentrations. This improved performance indicates that the shift from using annual coefficients and a linear time-dependent term added to Eq. (1) in version 1 to using coefficients computed over 5-month running temporal windows in version 4 does make the Pathfinder algorithm better able to account for temporally varying atmospheric effects.

Persistent cloudiness may also be important, as it limits the number of satellite retrievals available for creating the climatology. Maps of the number of observations used to generate the monthly mean SST (not shown) at each 9-km pixel show a band of reduced values just north of the equator, which reaches its largest areal extent in June, July, and August. This cloudiness is most intense in the eastern north-equatorial Pacific and Atlantic, and around Indonesia and the western Pacific, but is apparent even in the middle of the Atlantic and Pacific basins. Frequent cloudiness is also observed in other areas of the globe. For example, the Kuroshio and Gulf Stream regions are heavily cloud covered from December to March, when the air-sea temperature difference is great. However, even in these areas of high SST variability, the Pathfinder + erosion climatology, despite the persistence of clouds, is better able to minimize $\sigma$ than the other climatologies. Apparently, in these regions the in situ and blended climatologies are unable to adequately describe the mean state with their relatively coarse spatial resolutions. The Pathfinder + erosion climatology also generally outperforms the in situ and blended climatologies at higher latitudes, which are also characterized by persistent cloud cover. At the highest latitudes, however, the Pathfinder + erosion climatology must be regarded with more skepticism due to the presence of sea ice whose temperatures may be confused with actual SST by the Pathfinder algorithm.

High water vapor content in the tropical atmosphere is also known to create difficulties for the Pathfinder algorithm, which tends to undercorrect for atmospheric effects near the equator, resulting in satellite retrievals that are $0.1^{\circ}-0.2^{\circ} \mathrm{C}$ cooler than in situ SST on average (Evans and Podesta 1996). Overcorrection in the midlatitudes resulting in warmer satellite values relative to in situ SST measurements is also known to occur. Both of these traits were observed in the biases between the earlier version 1 Pathfinder + erosion climatology and the in situ data, as was a strong overcorrection in the warmest temperature classes (not shown). In the version 4 Pathfinder + erosion climatology, the same relative patterns are observed, but the biases have been shifted downward by about $0.1^{\circ} \mathrm{C}$ on average (Fig. 9). This shift indicates an overcorrection in the version 4 algorithm for all classes warmer than about $5^{\circ} \mathrm{C}$ in the Southern Hemisphere and $3^{\circ} \mathrm{C}$ in the Northern Hemisphere. The middle temperature classes around $18^{\circ} \mathrm{C}$ and the very warmest classes are more strongly corrected than the others, which tend to have small negative biases between about $-0.2^{\circ} \mathrm{C}$ and $0^{\circ} \mathrm{C}$. The plot of biases by temperature class (Fig. 9) also indicates biases in the WOA94 climatology, which may result from that climatology's use of $1^{\circ}$ zonal means as a "first-guess" for the climatological SST. The mid- and high latitudes, where temperature classes and latitudinal bands diverge the greatest, are also where the WOA94 climatology has the strongest biases.

The difficulties of persistent cloud cover and varying aerosol and water vapor content present a problem for the Pathfinder + erosion climatology in warm, lowlatitude regions, particularly in the Northern Hemisphere. These regions are characterized by generally lower SST variability than the middle and high latitudes, allowing the climatologies based on sparse spatial and temporal in situ coverage to adequately represent the mean SST state. This combination permits the $1^{\circ}$ in situ and blended climatologies to better minimize $\sigma$, but generally only in this region. In the Southern Hemisphere low latitudes, the Pathfinder algorithm faces some of the same difficulties, but there are even fewer in situ measurements on which to base an in situ climatology, resulting in similar or smaller $\sigma$ for the Pathfinder + erosion climatology. In the middle latitudes, generally higher SST variability and the presence of strong oceanic fronts are more fully captured by the higher spatial and temporal sampling of the satellite data, allowing the Pathfinder + erosion climatology to minimize $\sigma$ in the individual anomalies.

These results also point to the possibility of generating improved blended products like the $1^{\circ}$ Reynolds and GISST climatologies using Pathfinder data instead of MCSST and NLSST retrievals. The Pathfinder dataset provides more retrievals with better accuracy than the previous algorithms, and could possibly be blended with the in situ observations using a method that puts more emphasis on the satellite values than is being given by the current blending techniques. Another possibility is to define a weighting scheme for the in situ values based on the spatial homogeneity observed with the collocated Pathfinder satellite data.

Improvements to the AVHRR Pathfinder data between version 1 and 4 have been observed in this analysis. The use of algorithm coefficients generated over 5 -month running windows in version 4 instead of annual coefficients as in version 1 appears to have improved the SST retrievals in the presence of fluctuating atmospheric contaminants such as aerosols and water vapor. More years of data were also made available with version 4, allowing the resulting climatology to be even more complete than the earlier fields based on version 1 data. 


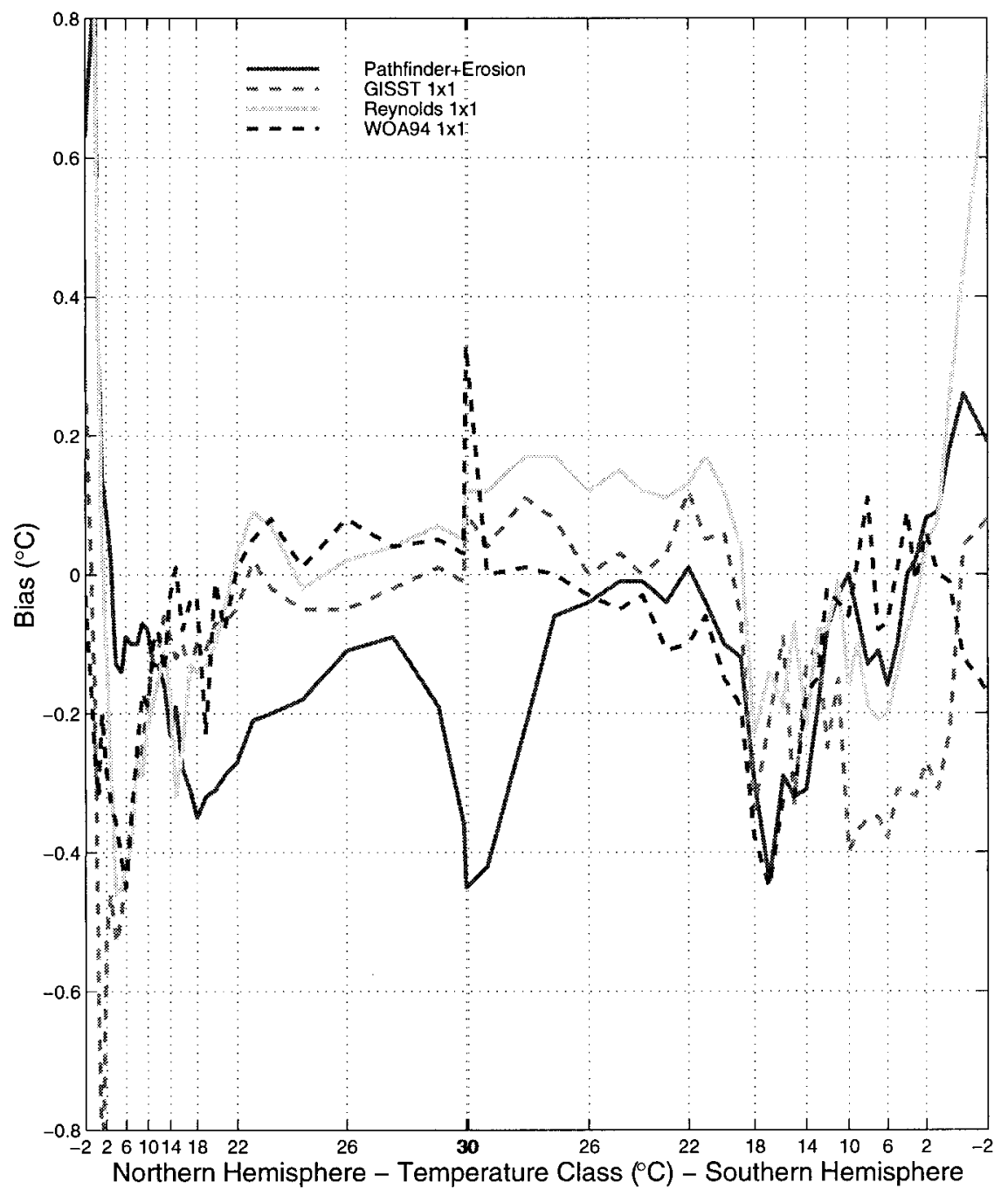

FIG. 9. WOA94 biases by temperature class. The mean difference, or bias, between WOA94 in situ observations and climatological SST is averaged annually and shown for the Pathfinder + erosion satellite climatology and the three $1^{\circ}$ in situ-based climatologies. The horizontal axis is weighted by the surface area of the ocean that the class occupies as in Fig. 4.

One of the Pathfinder + erosion climatology's distinguishing characteristics is its complete independence from the WOA94 in situ SST observations and its nearly complete independence from the COADS collection, except for the very small percentage of moored and drifting buoys that are used to tune the Pathfinder algorithm. The WOA94 climatology is derived directly from the WOA94 in situ observations using a technique that examines the observations in zonal bands, so it is not surprising that the WOA94 climatology performs well for the WOA94 anomalies in the latitudinal band binning scheme (Fig. 5a). Both the Reynolds and GISST climatologies rely on COADS in situ SST observations, and are seen to perform relatively well for the COADS anomalies. Because of these dependencies, the comparisons were also performed after excluding the de- pendent climatologies from the analysis. Upon removing the WOA94 climatology from the WOA94 anomaly $\sigma$ comparisons, the Pathfinder + erosion climatology has or shares the smallest $\sigma$ for all latitudinal bands except the $10^{\circ} \mathrm{N}, 20^{\circ} \mathrm{N}$, and $50^{\circ} \mathrm{S}$ bands (Fig. $5 \mathrm{~b}$ ), and it is found to minimize $\sigma$ over about $74 \%$ of the ocean surface. Its performance also improves in the temperature class comparisons (Fig. 4b), minimizing $\sigma$ over nearly $80 \%$ of the ocean surface. Similarly, when the GISST and Reynolds climatologies are removed from the comparisons involving the COADS anomalies, the Pathfinder + erosion climatology has the smallest values in all the bands, and improvements are also realized in the temperature class binning scheme (not shown). While the Pathfinder + erosion climatology performs well when compared with the dependent climatologies, 
its ability to minimize $\sigma$ in the SST anomalies is even more pronounced when compared with the independent climatologies.

The method of minimizing $\sigma$ presented here introduces a simple tool for evaluating a given climatology's suitability for the generation of SST anomalies. This method indicates that despite some low-latitude limitations, the 9-km Pathfinder + erosion climatology is generally better able to represent the SST spatial and seasonal variability than the in situ and blended climatologies. The performance of the Pathfinder + erosion climatology is particularly remarkable in light of the fact that it is completely independent from the WOA94 in situ SST data collection, and almost completely independent from the COADS observations. The individual anomalies generated in this study can now be examined over time using a variety of binning and averaging procedures to characterize long-term changes in global and regional SST.

Acknowledgments. This research was performed with support from NASA (NAGW3009) and salary support to P. Cornillon from the State of Rhode Island and Providence Plantations. Support was also provided to K. Casey during the revision process by the Universities Space Research Association. The satellite data processing software was developed by $\mathrm{R}$. Evans, O. Brown, J. Brown, and A. Li of the University of Miami. Their continued support is gratefully acknowledged. The Pathfinder data were obtained from the NASA Physical Oceanography Distributed Active Archive Center at the Jet Propulsion Laboratory, California Institute of Technology. Steve Worley of the National Center for Atmospheric Research Data Support Section provided the COADS data and the Reynolds and GOSTA climatologies. His assistance is greatly appreciated. John Merrill of URI/ GSO was also instrumental in obtaining the COADS data. We also thank David Parker of the U.K. Meteorological Office for permission to use the GISST climatology.

\section{REFERENCES}

Barton, I. J., 1995: Satellite-derived sea surface temperatures: Current status. J. Geophys. Res., 100, 8777-8790.

Bates, J. J., and H. F. Diaz, 1991: Evaluation of multichannel sea surface temperature product quality for climate monitoring: 1982-1988. J. Geophys. Res., 96, 20 613-20 622.

Bottomley, M., C. Folland, J. Hsiung, R. Newell, and D. Parker, 1990: Global Ocean Surface Temperature Atlas (GOSTA). United Kingdom Meteorological Office and Massachusetts Institute of Technology, 20 pp. and 313 plates.

Brown, J. W., O. B. Brown, and R. H. Evans, 1993: Calibration of Advanced Very High Resolution Radiometer infared channels: A new approach to nonlinear correction. J. Geophys. Res., 98, 18 257-18 268.

Clancy, R. M., and R. A. Weller, 1992: Sea surface temperature, ad hoc working group report. Tech. Rep., Joint Oceanographic Institutions, Inc., Washington, DC, 52 pp. [Available from Joint
Oceanographic Institutions, Inc., 1755 Massachusetts Ave. NW, Suite 800, Washington, DC 20036-2102.]

Cushman-Roisin, B., 1994: Introduction to Geophysical Fluid Dynamics. Prentice-Hall, 320 pp.

Evans, R., and G. Podesta, 1996: AVHRR Pathfinder SST approach and results. Eos, Trans. Amer. Geophys. Union, 77 (Suppl.), F354.

Folland, C., and D. Parker, 1995: Correction of instrumental biases in historical sea surface temperature data. Quart. J. Roy. Meteor. Soc., 121, 319-367.

- T. Karl, and K. Vinnikov, 1990: Observed climate variations and change. Climate Change, The IPCC Scientific Assessment, J. Houghton, G. Jenkins, and J. Ephraums, Eds., Cambridge University Press, 195-238.

,-- , N. Nicholls, B. Nyenzi, D. Parker, and K. Vinnikov, 1992: Observed climate variability and change. Climate Change 1992: The Supplementary Report to the IPCC Scientific Assessment, J. T. Houghton, B. A. Callander, and S. K. Varney, Eds., Cambridge University Press, 135-170.

Gong, X., and M. B. Richman, 1995: On the application of cluster analysis to growing season precipitation data in North America east of the Rockies. J. Climate, 8, 897-931.

Houghton, J. T., G. J. Jenkins, and J. J. Ephraums, Eds., 1990: Climate Change, The IPCC Scientific Assessment. Cambridge University Press, $365 \mathrm{pp}$

_ L. G. Meira Filho, B. A. Callander, N. Harris, A. Kattenberg, and K. Maskell, Eds., 1996: Climate Change 1995: The Science of Climate Change. Cambridge University Press, 572 pp.

Jones, P., T. Wigley, and G. Farmer, 1991: Marine and land temperature data sets: A comparison and a look at recent trends. Greenhouse-Gas-Induced Climatic Change: A Critical Appraisal of Simulations and Observations, M. Schlesinger, Ed., Elsevier, $153-172$.

JPL PO.DAAC, cited 1998: NOAA/NASA AVHRR oceans Pathfinder sea surface temperature data set user's guide. [Available online at http://podaac.jpl.nasa.gov/pub/sea_surface_temperature/avhrr/ pathfinder/doc/usr_gdel_3.html.]

Levitus, S., and T. Boyer, 1994: World Ocean Atlas 1994. Vol. 4, Temperature: NOAA Atlas NESDIS 4, NOAA/National Environmental Satellite, Data and Information Service, $117 \mathrm{pp}$.

McClain, E. P., W. G. Pichel, and C. C. Walton, 1985: Comparative performance of AVHRR based multichannel sea surface temperatures. J. Geophys. Res., 90, 11 587-11 601.

Nicholls, N., G. V. Gruza, J. Jouzel, T. Karl, L. Ogallo, and D. Parker, 1996: Observed climate variability and change. Climate Change 1995: The Science of Climate Change, J. Houghton, et al., Eds., Cambridge University Press, 133-192.

Parker, D., P. Jones, C. Folland, and A. Bevan, 1994: Interdecadal changes of surface temperature since the late nineteenth century. J. Geophys. Res., 99, 14 373-14 399.

—- M. Jackson, and E. Horton, 1995: The 1961-1990 GISST2.2 sea surface temperature and sea-ice climatology. Hadley Centre Climate Research Tech. Note 63, Hadley Centre for Climate Prediction and Research, 35 pp. [Available from Hadley Centre for Climate Prediction and Research, Meteorological Office, London Rd., Bracknell, Berkshire RG12 2SY, United Kingdom.]

Podesta, G., K. Kilpatrick, S. Shenoi, J. Brown, and R. Evans, cited 1998: AVHRR Pathfinder oceans matchup database 1985-1996 (version 19.0). [Available online at http://www. rsmas.miami.edu/ gui/v19/matchups.v19.0.html.]

Rayner, N., E. Horton, D. Parker, C. Folland, and R. Hackett, 1996: Version 2.2 of the global sea-ice and sea surface temperature data set. Hadley Centre Climate Research Tech. Note 74, Hadley Centre for Climate Prediction and Research, 35 pp. [Available from Hadley Centre for Climate Prediction and Research, Meteorological Office, London Rd., Bracknell, Berkshire RG12 2SY, United Kingdom.]

Reynolds, R., 1988: A real-time global sea surface temperature analysis. J. Climate, 1, 75-86. 
- , and T. Smith, 1994: Improved global sea surface temperature analyses using optimum interpolation. J. Climate, 7, 929-948.

- , and -1995 : A high-resolution global sea surface temperature climatology. J. Climate, 8, 1571-1583.

Schluessel, P., W. J. Emery, H. Grassl, and T. Mammen, 1990: On the skin-bulk temperature difference and its impact on satellite remote sensing of sea surface temperature. J. Geophys. Res., 95 13 341-13 356

Schollaert, S. E., 1996: The relationship between aerosol optical thickness and sea surface temperature variations. M.S. thesis, Graduate School of Oceanography, University of Rhode Island,
64 pp. [Available from Graduate School of Oceanography, University of Rhode Island, Narragansett, RI 02882.]

Trenberth, K. E., J. R. Christy, and J. W. Hurrell, 1992: Monitoring global monthly mean surface temperatures. J. Climate, 5, 14051423.

Walton, C., 1988: Nonlinear multichannel algorithms for estimating sea surface temperature with AVHRR satellite data. J. Appl. Meteor., 27, 115-124.

Woodruff, S., S. Lubker, K. Wolter, S. Worley, and J. Elms, 1993: Comprehensive Ocean-Atmosphere Data Set (COADS) release 1a: 1980-92. Earth Syst. Monit., 4, 1-8. 